\title{
Artigo de dados de fragmentos de lenhos carbonizados de Araucariaceae a partir de análise de infravermelho (FTIR)
}

Daniela Mueller de Lara', Simone Stülp²

\footnotetext{
Engenheira Ambiental, Professora Doutora na Universidade Estadual do Rio Grande do Sul (UERGS), Unidade Alto da Serra do Botucaraí em Soledade/RS, Brasil.

E-mail: daniela-lara@uergs.edu.br

2 Química, Professora Doutora na Universidade do Vale do Taquari, Lajeado/RS, Brasil.

E-mail: stulp@univates.com.br
}

\section{Resumo}

Os dados fazem parte de uma tese de doutorado que objetivou desenvolver uma metodologia para avaliar por métodos físicos e químicos os lenhos carbonizados artificialmente de três espécimes da família Araucariaceae: Araucaria angustifolia, Araucaria bidwillii e Araucaria columnaris. O processo de carbonização dos fragmentos dos lenhos foi realizado em mufla. As temperaturas da queima dos lenhos in natura carbonizados foram de $200^{\circ} \mathrm{C}$ a $600^{\circ} \mathrm{C}$, variando-se a temperatura de $50^{\circ} \mathrm{C}$ em $50^{\circ} \mathrm{C}$ e com taxa de aquecimento avaliada em $25^{\circ} \mathrm{C} \mathrm{min}-1$. Posteriormente ao processo de carbonização, os espectros foram adquiridos no espectrofotômetro de infravermelho, num intervalo entre 1900 a 650 $\mathrm{cm}^{-1}$, com resolução de $4 \mathrm{~cm}^{-1}$ e 64 varreduras.

Palavras-chave: Araucariaceae. Carbonização em mufla. Espectroscopia de infravermelho.

\section{Abstract}

\section{Data article of Araucariaceae carbonized wood fragment from infrared analysis (FTIR)}

Data are part of a doctoral thesis that aimed developing a methodology to evaluate, by physical and chemical methods, the artificially carbonized wood of three specimens of the Araucariaceae family: Araucaria angustifolia, Araucaria bidwillii and Araucaria columnaris. The carbonization process of the wood fragments was carried out in a muffle. The burning temperatures of the carbonized in nature wood were from $200^{\circ} \mathrm{C}$ to $600^{\circ} \mathrm{C}$, with a temperature ranging from $50^{\circ} \mathrm{C}$ to $50^{\circ} \mathrm{C}$ and with a heating rate of $25^{\circ} \mathrm{C} \mathrm{min}{ }^{-1}$. After the carbonization process, the spectra were acquired in the infrared spectrophotometer, in an interval between 1900 to $650 \mathrm{~cm}^{-1}$, with a resolution of $4 \mathrm{~cm}^{-1}$ and 64 scans.

Keywords: Araucariaceae. Carbonization in muffle. Infrared spectroscopy.

Artículo de datos de fragmentos de leños carbonizados de Araucariaceae a partir del análisis de infrarrojo (FTIR)

\section{Resumen}

Los datos hacen parte de una tesis doctoral que objetivó desarrollar una metodología para evaluar por métodos físicos y químicos los leños carbonizados artificialmente de tres especímenes de la familia Araucariaceae: Araucaria angustifolia, Araucaria bidwillii y Araucaria columnaris. El proceso de carbonización de los fragmentos de los leños fue realizado 
en mufla. Las temperaturas de la quema de los leños in natura carbonizados fueron de $200^{\circ} \mathrm{C}$ a $600^{\circ} \mathrm{C}$, variándose la temperatura de $50^{\circ} \mathrm{C}$ en $50^{\circ} \mathrm{C}$ y con la tasa de calentamiento evaluada en $25^{\circ} \mathrm{C} \mathrm{min}$. $^{-1}$. Posteriormente al proceso de carbonización, los espectros fueron adquiridos en el espectrofotómetro de infrarrojo, en un intervalo entre 1900 a 600 $\mathrm{cm}^{-1}$, con resolución de $4 \mathrm{~cm}^{-1}$ y 64 escaneos.

Palabras clave: Araucariaceae. Carbonización en mufla. Espectroscopía de infrarrojo.

\section{Coleta dos dados}

\section{Identificação das amostras}

Fragmentos de lenhos de três espécies de Araucariaceae foram coletados em diferentes localidades do Rio Grande do Sul, Brasil. Os espécimes foram extraídos por motivos diversos em áreas dos municípios de

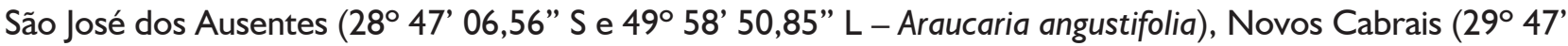

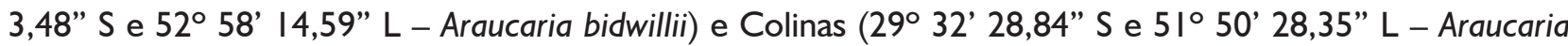
columnaris). As amostras foram obtidas em forma de discos a $1,50 \mathrm{~m}$ de altura, medindo $8 \mathrm{~cm}$ de espessura e 18 a $35 \mathrm{~cm}$ de diâmetro.

Para a identificação dos lenhos das espécies da família Araucarieaceae um código composto de letras e numerais foram utilizados. A primeira letra identifica qual a família $(A)$ e a segunda identifica qual a espécie (a), em minúsculo. O código posterior à identificação das letras representa as temperaturas de queima. As mesmas serão representadas numericamente. $O$ processo de carbonização foi identificado com a letra $M$ (Mufla). Por fim, posterior ao processo de queima, um número indicará a reprodução da análise, sendo que para cada temperatura de amostra de lenho carbonizado artificialmente serão realizadas três réplicas.

\section{Processo de carbonização em mufla}

Os lenhos in natura foram carbonizados em mufla SP Labor (modelo SP- I200). As amostras foram cortadas com dimensões de $1,0 \mathrm{~cm} \times I, 0 \mathrm{~cm} \times 1,0 \mathrm{~cm}\left(I, 0 \mathrm{~cm}^{3}\right)$, com variância de $0,02 \mathrm{~cm}$. Posteriormente, no cadinho de porcelana (Chiarotti A-37) foi depositada uma quantidade de areia suficiente para preencher o fundo do mesmo. Após essa etapa, a amostra previamente pesada foi colocada dentro do cadinho de porcelana e, objetivando restringir a quantidade de oxigênio no processo de carbonização, o recipiente foi preenchido até sua borda com areia do mar purificada (Merck) com ácido e calcinada, cujo tamanho de partículas varia de $0, \mathrm{I}$ a $0,3 \mathrm{~mm}$.

As temperaturas da queima dos lenhos in natura foram feitas num intervalo de $200 \mathrm{a} 600^{\circ} \mathrm{C}$, variando-se a temperatura de $50 \mathrm{em} 50^{\circ} \mathrm{C}$ e com taxa de aquecimento avaliada em $25^{\circ} \mathrm{C} \mathrm{min}{ }^{-1}$. As análises foram realizadas em triplicata para cada temperatura de queima e para cada uma das três espécies avaliadas, totalizando 81 amostras.

Para o processo de carbonização, a temperatura de aquecimento do forno mufla era regulada a 50 ${ }^{\circ} \mathrm{C}$ por 5 minutos para estabilização. Após esse tempo, as amostras foram colocadas no interior da mufla, ajustando-se a temperatura desejada. Quando o equipamento atingia a temperatura estipulada, a amostra permanecia no forno por 60 minutos. Posterior a esse período, as amostras eram retiradas da mufla e acondicionadas em dessecador até atingir peso constante.

\section{Obtenção dos espectros de IR}

Os espectros foram adquiridos no espectrofotômetro SHIMADZU, modelo IR Affinity-I. Antecedendo as leituras dos espectros, foi realizado a preparação das amostras de lenhos carbonizados artificialmente a partir da confecção da pastilha de $\mathrm{KBr}$. Subsequente à fabricação da pastilha, os espectros foram adquiridos no espectrofotômetro de infravermelho, num intervalo entre 1900 a $650 \mathrm{~cm}^{-1}$, com resolução de $4 \mathrm{~cm}^{-1}$ e 64 varreduras. Para a aquisição dos espectros no infravermelho médio foi realizado primeiramente a leitura do branco (background).

\section{Planilha de dados}

Para acessar a planilha de dados: https://doi.org//0.6084/m9.figshare. | 294723 I.vI 


\section{Como citar os dados da pesquisa}

Mueller de Lara, Daniela (2020): Dados de pesquisa Fragmentos de lenhos Araucariaceae .xls. figshare. Dataset. https://doi.org/I0.6084/m9.figshare. I 294723I.vI

\section{Referências}

LARA, D. M. de. Avaliação química de lenhos carbonizados de espécies da araucariaceae: caracterização de materiais associada à análise multivariada para inferências (paleo)ambientais. 134 p. Tese de Doutorado. Universidade do Vale do Taquari - Univates, 2017.

LARA, Daniela M. de et al. Avaliação de fragmentos de lenhos carbonizados de araucariaceae por meio de termogravimetria e infravermelho associadas à análise multivariada. Quím. Nova, São Paulo, v. 40, n. 8, p. 895-90I, Sept. 2017. http://dx.doi.org/10.2 I577/0100-4042.20 I70095. Disponível em: http://www.scielo.br/scielo.php?script=sci_arttext\&pid =SOI00-404220I7000800895\&Ing=en\&nrm=iso Acesso em: 30 Jan. 2020. 